\title{
El estudio de la historia contemporánea
}

\begin{abstract}
A R NOL D T O Y X B E es el autor de $A$ Study. of History (Oxford University Press) y fue por varios años profesor de asuntos internacionales en el Royal Inscitute of International Affairs en Londres. Este articulo cstá. tomado de una conferencia dictada en el Salón de Honor de la Universidad de Chile. el 24 dc octubre de 1966.
\end{abstract}

La fundación de un Instituto de Estudios Internacionales se basa en el supuesto de que el estudio de la historia conternporánea es posible. La que se estudia en estos institutos son, precisamente, los asuntos internacionales contemporáneos, los calales toman parte de la historia general contemporánea. Pero esto es un supuesto $y$, por consiguiente, puede ser objetado. Se puede argumentar diciendo que el estudio serio, objetivo y científico de los asuntos internacionales no es realmente factible, ya que cuando se está tan cerca de los acontecimientos, no se les puede estudiar más que en forma periodística. Por eso quiero discutir aquí este problema fundamental: si el estudio de la historia contemporáneà -el estudio serio de clla- es realmente factible.

$\therefore$ Se supone que es posible estudiar la historia contemporánea en cualquier país que, como éste, el mío o los Estados Unidos de Norteamérica, posea una constitución democrática. Después de todo, el ideal politico del mundo actual es la democracia. Aún los regínenes no démocráticos, que supongo están en mayoria en el mundo, consideran la democracia como un ideal deseable. La democracia sólo tendrá éxito si el pais trata de gobernarse a si mismo demo. cráticamente y si cuenta con un gran número de ciudadanos activos, efectivos y con espíritu cívico. No se puede ser un ciudadano efectivo sin algún conocimiento y comprensión del mundo en el cual uno se cncuentra, y no se puede comprender al mundo si no se está al tanto del continuo desenvolvimiento. La evolución del mundo en el cual vivimos es la historia contemporánca. De alli que en cualquier pais democrítico, y yo diria que, en cualquier pais donde el pucblo realmente desea tomar parte inteligente y actira en los asuntos públicos, debemos tratar de estudiar la historia contemporánea.

De. lo anterior podemos concluir que es descable el estudio de la historia contemporánea, pero ébemos averiguar si es factible. Un espíritu crítico podria objetar la posibilidad de estudiar la historia contemporánea fundándose, por lo menos, en tres razones: 
La primera razón para suponer que el estudio de los asuntos contemporáncos es imposible, proviene de la falta de información fidedigna de los acontecimientos actuales. La politica, especialmente la internacional, es todavia uno de los aspectos más atrasados de la vida sociohumana. Tanto en nuestra vida familiar como en el trabajo, somos mucho más civilizados que en nuestra vida política y especialmente más que en las relaciones internacionales que mantienen los estado independientes. La politica internacional está aún en una etapa muy primitiva y salvaje, y donde la vida es salvaje hay violencia, y debido a la violencia hay miedo, y debido al miedo hay cautela. La conducta de todo pais, en cuanto a sus relaciones exteriores aún del más civilizado, pacifico y cooperador, está hoy mucho más llena de reservas que las que existen en los asuntos domésticos y más aún, de lo que se acostumbra en casi todoos los' demás aspectos de la actividad humana. Mientras más importante sea un acuerdo internacional, es probable que más cautelosos scan aquellos que están involucrados en él. Aqui también debo señalar que los documentos cruciales, aquellos realmente confidenciales, los documentos claves, rara vez se publican in: mediatamente despuès del acontecimiento. Lo que se publica en la prensa es aquella información obtenida por fuentes extraoficiales momentos después de ocurrido el acontecimiento, y si la prensa logra alguna información de tal o cual gobiemo, emitida por el Departamento de Relaciones Públicas del Ministerio de Relaciones Exteriores de un país, ésta, por supuesto, no será desintere: sada y totalmente objetiva; será el panorama que ese gobierno en particular desea dar a conocer al mundo respecto al acuerdo en que ha participado. Por lo demás, el quien refute la posibiliclad del estudio de la historia contemporánea podria añadir que los acontecimientos actuales pueden ser, por supuesto, materia periodística, ya que los artículos periodísticos no representan más que conjeturas provisionales y efimeras, que más adelante serán reemplazadas por estudios más sustanciales y objetivos. Por lo tanto, aunque pudiera haber una relación periodistica de los acontecimientos contemporáneos ise podría escribir una historia seria de tales acontecimientos? La respuesta de estos críticos seguramente sería que "No".

Llegamos a la scgunda objeción que expondria el crítico y ésta se refiere a que si los acontecimientos han ocurriclo tan recientemente, digamos, hace seis o dieciocho meses atrás, no podriamos apreciarlos en perspectiva. Agregaria que la perspectiva y la proporción son obra del tiempo. Sólo a través del tiempo podemos juzgar el comportamiento de los diferentes gobiernos involucrados. Diciendo que la perspectiva es obra del tiempo, aún dicciocho meses no es tiempo suficiente para obtener una visión correcta; en 50, 100 ó 500 años se podrá apreciar la historia en su verdatera proporción. Esta seria Ja segunda objeción de aquellos que estín considerando seriamente el cstudio de la historia contemporánea.

La tercera objeción es quizás la más seria de todas. Iil cricico diria que el investigator o el historindor aismo forma parte de los acontecimientos con- 


\section{E. STLDIOS INTER N ACIONALES}

cemporíncos; por lo que no puecle desligarse de cllos. Es probable que el investigador tenga sentimientos parciales acera de los acontecimientos y éstos distorcionarian su juicio. Respecto a la cuesción racial, por ejemplo, cstará violentamente a favor de la integración de diferentes razas o bien estará violentamente a favor de la discriminación, como lo está la minoría de blancos en Sudífrica; en cuanto al asunto de Vietnam, estará a favor de la politica y acción de los Estados Unidos o en contra de ella, y así sucesivamente, No cstará en condiciones de describir en forma calmada, desinteresada y objetiva estos acontecimientos, describir, digamos la política del gobierno sudafricano, lo que ocurre actualmentc en Rhodesia y lo que estai ocurriendo en Vietnam. Ahora bien, el critico puede decir que si el historiaclor ha de ser imparcial u objetivo, debe abocarse a lo que hoy ha llegado a ser historia antigua, significando por "antigua" la historia de un períoclo para el cual ninguno de los personajes involucrados existe hoy y ṇinguno de los acuerdos tienen ya incidencia en los asuntos actuales. Quizás con respecto a historia antigua es posible que el historiador sea imparcial, pero no con respecto a los acontecimientos de su propia época y mucho menos con respecto a los acontecinientos actuales.

Creo que cada una de estas tres objeciones respecto a la posibilidad real de estudiar la historia contemporánea es importantc, pero considero que sobre cada una de ellas hay algo favorable que decir. Ne permito mencionar algo personal; mi esposa y yo apostaríamos nuestras vidas, por decirlo así, a que es posible escribir una seria historia contemporánea, ya que hemos pasado treinta y tres años en el Royal Institute of International Affairs en Londres, tratando de escribir un estudio de los asuntos contemporáneos actuales.

Ahora tomaré estas tres objeciones en el orden que las he mencionado, discutiendo cada una de ellas.

Es muy cierto que en la mayoría de los casos los documentos oficiales no se publican hasta quizás medio siglo después de haber sido escritos, y cuando scan publicados el historiador futuro obtendra la información que el historiador contemporáneo no posee. Mi esposa y yo tuvimos esta experiencia al finalizar la Seguinda Guerra Mundial. Durante la guerra escribíamos la historia de relacioneș internacionales contemporáneas, año a año, en base a fuentes extraoficiales - con excepción de escasos documentos oficiales publicados- obteniclos principalmente de los artículos aparecidos en periódicos de distintos paises. Al finalizar la guerra publicamos una historia política $y$ económica de la Segunda Guerra Mundial y aquí contamos con otro tipo de información, además de la obtenida de los periódicos. Los aliaclos aprovecharon su victoria para recopilar los documentos oficiales alen anes del periodo nazi y del anterior a éste, publicándolos poco tiempo clespués de la guerra. Por supuesto estos documentos cran fuentes informativas de primer orden deste el punto de vista de uno de los participanes de la Segunda Guerra Mrundial. Los gobiernos aliaclos: el británico, el americano y el francés tam. bién comenzaron a publicar sus propios docunentos oficiales del mismo pe- 
riodo, de manera que duranie los xis 0 mis años en que escribiumos la hiscoria de la Segunda Gucra Mundial, contábanos con cierta canticlad de in. fomación contemporánca olicial. Efectivamente. esto nos dio una visión diferente de los acontecimientos de la que hubiéramos teniclo si sólo hubieramos contado con las informaciones de los periúdicos.

Al mismo tiempo, los documentos oficiales tienen limitaciones que son familiares a cualquier persona que haya trabajaclo temporalmente, como yo, o como funcionario permanente, en cualquier ministerio de cualquier gobierno y haya tomado parte en la deducción de estos documentos. Una vez que se ha participado en la redacción de documentos oficiales, sc.es menos ingenuo con respecto al valor de cllos como materia para el estudio de la história.

Los documentos oficiales nunca son redactaclos para proporcionar información a los historiadores, ya que aquéllos, los que redactan, son personas prácticas y no es su propósito hacerles un servicio a los futuros historiadores; no piensan ni en los historiadores futuros ni en los contemporáneos. Los documentos oficales se redactan con propósitos de acción y de acción inmediata; con el fin de provocar un suceso o bien para prevenir el acontecimiento. No son redactados primordialmente con la finalidad de dar un relato objetivo e imparcial que sería útil a un historiador. Los documentos son formas de acción o, más bien, son una especie de huella dejada por la acción; no son lo que un historiador o aun un periodista trata de hacer, es decir, dar un relato desinteresado e imparcial de los acontecimientos.

Las ponas que redacian documentos oficiales están siempre muy ocupadas; siempre apuradas y recargadas de trabajo; esto último fundamentalmente en tiempos de crisis, que son naturalmente, los tiempos en los que el historiador está más interesado. Por eso, los funcionarios y ministros de Estado que redactan documentos dan por sabido hechos que son de conocimiento general en los círculos internos de las personas que están elaborando la política, llevándola a cabo en representación de tal o cual estado. De manera que los documentos omiten gran cantidad de hechos que se dan por conocidos. A menudo, lo que los documentos no mencionan son datos esenciales para su interpretación. El historiador que trabaja en un documento puede que haya tenido que esperar cincuenta años desde el día en que fue redactado, ya que debe ser sacado de los archivos secretos y puesto a disposición de los historiadores. Nio tendrá ninguna información acerca de aquellas omisiones que el documento da por sabidas. Si no se está informado sobre de lo omitido en el documento, es probable que éste no sea correctamente interpretado.

Algunos historiadores que no han tenido la oportunidad de trabajar temporalmente como funcionarios de gobierno $y$ que, por lo tanto, no han participado en la redacción de documentos, no han apreciado el porqué de su confección y propúsito. A veces los historiadores consideran los documentos como algo simple, comparándolos con el estrato geológico que estudia el 
geólogo. Supongo que el estrato no engaña, pues no tiene el ingenio para hacerlo; es algo inerte y por lo tanto sólo muestra la verdad. Un documento es obra del hombre y creado para un propósito. Sus autores no están particularmente interesados en relatar la verdad por lo que si se considera que un documento es una formación geológica, una información objeciva que no puede engañar, se puede incurrir en grandes errores. Para interpretar el documento correctamente y para obtener de él conocimientos históricos latentes, no sólo se debe contar con el texto, sino que también se necesita conocer sus antecedentes y éstos probablemente son desconocidos para el historiador. Los documentos publicados se componen generalmente de notas, memorándum y minutas escritas por varios funcionarios y ministros. El documento final que prevalece es el resultado de comentarios, sugerencjas y argumentos. El ministro poseerá todo el archivo que contiene las minutas anteriores que dieron como resultado el documento $y$ asi comprenderá por qué éste ha tomado tal ctirso. Pero los documentos pueden conducir a los futuros historiadores a conclusiones erróneas, especialmente si ellos son tan ingenuos como nara creer que contienen la verdad, toda la verdad y nada más que la verdad y si creen que se pueden comparar con estratos geológicos que son incapaces de engañar.

Por otro lado, una parte importante de los hechos históricos no son los acontecimientos concretos, sino los sentimientos y pensamientos acerca de ellos, experimentados por los participantes o los perjudicados. El historiador contemporáneo participa personalmente de la época sobre la cual escribe: conoce, por lo menos por experiencia, algunos de los sentimientos, pensamientos y emociones producidas en las mentes y corazones humanos por los acontecimientos de su época. El historiador que escribe cincuenta años más tarde cuenta con el documento escrito, pero no con la experiencia de haber vivido a través de los acontecimientos sobre los que trata el documento. Este ha perdido probablemente, la parte emocional. Por otro lado, el historiador contemporánco puede no tener acceso a los documentos oficiales, pero si puede tener acceso dentro de si mismo a los sentimientos y pensamientos comunes de la época, y' esto es una parte importante de la historia. Es por eso que creo que los relatos escritos muy poco tiempo despues de ocurrido el acontecimiento, dentro de seis o dieciocho meses, aunque por un lado serán reemplazados cuandio los documentos sean publicados, por otro lado siempre deberán ser consultados y'a que transmiten los sentimientos, por decirlo asi, de las personas que vivian durante aquellos aconterimientos. Por esto creo que la narración contemporánea mantendrá un valor permanente.

La segunda objeción que mencioné cra que si se escribe acerca de Jos acontecimientos ocurridos un recientemente como seis a dieciodro mescs atrís, no se aprecian en perspectiva, ya que el tiempo acomoda y coloca los hechos en su vendadern perspectiva. Considero que esta creencia sobre la obra slel tiempo es [alsa. El transeurso del tiempo economiza al historiador 
el trabajo y responsabilidad de dar una forma a los acontecimientos que está describiendo y le permite cludir el trabajo de juxgarlos ya que pasado cierto tiempo la forma de los acontecimientos y los juicios sobre ellos, aunque se juzguen buenos o malos, perversos o virtuosos, ya habrán tomado una forma concreta. Se habrán cristalizado en una forma determinada; se someterán al historiador ya claborados por sus predecesores y ya no estará en su poder ju-garlos por si mismo. Pero mientras esto le ahorra trabajo al historiador, lo priva de llegar a la verdad. El paso del tiempo crea un cuadro convencional, fijo de los acontecimientos pasados, obstaculizando al futuro historiador en su intento de llegar a la verdad, lo que es impeditivo para un relato objetivo de la historia. El-efecto del tiempo, generalmente. es para dar a uno de los personajes dramáticos, uno de los actores del drama, la oportunidad de monopoljzar el relato.

Ilustremos esto por medio de dos períodos de historia antigua: La his. toria de los antiguos griegos y de los antiguos sirios en el último milenio a. C. Por supuesto, ahora contamos con narraciones escritas acerca de la historia de Grecia y de Siria del último siglo a. C., pero cada uno de estos relatos, debido al transcurso del tiempo, refleja enteramente el punto de vista de uno de los actores en particular. Vemos la historia de la Grecia antigua en los siglos cruciales quinto y cuarto, no a través de los ojos de toda la población de los muchos cientos de estados soberanos de la Grecia antigua; vemos esta época de la historia griega sólo a través de los ojos de un pueblo: el pueblo de Atenas, ya que los atenienses, siendo personas de gran cultura literaria y de: gran poder intelectual lograron monopolizar el relato. Por Io que, todo el relato de estos acontecimicntos no fue escrito desde el punto de vista griego en general, sino que está escrito sólo según el punto de vista ateniense y la historia está narrada como ellos desearon que lo estuviera. Si la historia de Grecia del siglo quinto hubiera sido escrita por los espartanos o por los boecianos, tendriamos un panorama muy diferente del que tenemos.

En realidad, a este respecto la arqueologia viene en nuestra ayuda, los atenienses representan a los espartanos y boecianos como gente incivilizada, inculta y tosca, pero los descubrimientos arqueológicos demuestran que esto está lejos de la realidad y que ellos también fueron dignos exponentes del arte, la cultura y la civilización griega, mano a mano con los atenienses.

Volvamos ahora a la historia de la Siria antigua, en el último milenio a. C. Existian alli diversas comunidades semejantes a la de Grecia antigua: tres ciudades-estados f́nicios, cinco ciudades-estados filistcos, los reinos de Israel, de Judea, de Amón, Moab y de Damasco. Existia un número de estados diferentes, que mantenian entre si relaciones internacionales, negociaciones, guerras. Cada uno de ellos observaba estos acontecinientos desde su propio punto de vista. Sólo disponemos la visión que se tenía en el reino de Judea, uno de los mís pequeños y unás insignificantes de los diversos estados de Siria. Aún no remos la historia de Israel a tmvés de los ojos de Isracl: sólo la 
vemos como el pucblo de Judea y lo hizo, cicrtamente, no vemos la historia de los filisteos o de los fenicios tat como cllos la habrian descrito. Nucva. mente el pucblo de Judea escribió la historia que nos ha llegado a traves de los libros del Antiguo Testamento, y no tenemos documentos de los innumerables otros estados de Siria. De tal manera vemos toda la historia de Siria sólo a través de los ojos de los hebreos, tal como vemos las historias de Grecia sólo a través de los atenienses; y si tuviéramos documentos de los acontecimientos recogidos en los libros de historia del Antiguo Testamento escritos por algunos ciucladanos de Tiro o Sidón o de algunas de las ciudades filisteas, tendriamos un panorama bastante diferente de lo que más ha dejado la Biblia de aquellos acontecimientos. Pero, desgraciadamente, estos documentos no existen. De modo que no podemos comprobar ni controlar los testimonios hebreos por medio de las crónicas escritas por pueblos no hebreos de los estados que participaban en los acontecimientos a los cuales se refieren los escritores hebreos de los libros del Antiguo Testamento.

Resulta pues, que a través de tanta historia acumulada, de historia antigua, no tenemos sino una opinión parcial que podria equivaler más o menos a una opinión partidariā. Es imposible esperar que sea una opinión objetiva, tomando en cuenta todos los puntos de vista de las partes comprometidas. Obtendremos sólo la opinión de la parte que monopolizó el relato. No podemos ir más allá de esta visión partidaria, ya que no poseemos otras fuentes de información contemporánea que ofrezcan otros puntos de vista que nos sirvan de control.

La arqueologia Siria, nuevamente, ha venido en nuestra ayuda hasta cierto punto, ya quie nos legó algunos documentos fenicios y algunos objetos materiales de la civilización de los filisteos, además de algunos del reino de Israel y de Judea. Pero éste es un material bastante magro para poder equilibrar el inmenso peso de los relatos del Antiguo Testamento.

Nuestro conocimiento actual de una gran parte de la historia antigua se deriva de alguna obra particular, que ni siquiera es un trabajo original contemporáneo, sino que en muchos casos, un trabajo secundario que no indica sus fuentes de información. De tal manera que no podemos decir de dónde derivó este trabajo secundario. No nos indica sus parcialidades ni prejuicios o cuales fueron sus fuentes de parcialidades o prejuicios. Tenemos entonces este solo testimonio secundario y nuevamente no podemos comprobarlo ni controlarlo. Pero, si un historiador escribe sobre acontecimientos muy recientes, está en una posición mejor en este sentido que el que está escribienclo sobre sucesos muy antiguos. Cuando los acontecimientos son muy recientes, es dificil que un solo particlo haya alcanzado a monopolizar el rela to. Por ejemplo, si uno esta iratando de escribir la historia de la Segunda Guerra Mfundial o aun algo anterior, como la Primera Guerra Mundial, se obtendrá no sólo el testimonio de las maciones vencidas, los alemanes, los húngaros, etc., sino también el de las naciones vencedoras. Entonces se podrá 
comparar cstos relatos. uno con el otro, y formar su propio juicio a la luz de estos acontecimientos probablemente conflictivos, precisamente porque cl tiempo transcurrido es muy reciente y nadic ha tenitio la posibilidad de monopolizar cstos relatos. Por ello, diria que la perspectiva de ticmpo es una perspectiva falsa. El panorama que ha llegado a ser convencional será muy diferente del verdadero, por las razones yia cxpuestas.

La tercera objeción es que ci historiador, al cscribir sobre acontecimientos contemporíneos de su propin época -acontecimientos del momento-, está implicado emocionalmente en cllos de manera que no puede desligarse, ni ser imparcial, en su relato. Por supuesto esto es valedero jiara la relación del historiador respecto a la historia de su propio tiempo y también lo es para la relación del historiador con la historia de cualquier época, por remota que sèa.

En realidad, la implicación emocional del historiador en los acontecimientos contemporáneos es caracteristica de la actitud del historiador frente a toda la historia humana. Cuando un ser humano está estudiando la naturaleza no humana - la flora o la fauna del país, formaciones geológicas, la naturaleza y el movimiento de los astros, los átomos, electrones y protonessupongo que no tiene prejuicio a favor de tal o cual electrón, éste o el otro protón, éste u otro estrato geológico, etc. Está totalmente desligado, imparcial y objetivo en su estudio de la naturaleza no-humana. Pero cuando un historiador está estudiando los sucesos humanos, las experiencias humanas, los sufrimientos humanos, aun cuando éstos alcancen los limites del pasado tendrá sentimientos humanos respecto a ellos, porque cualquier ser humano participa de cualquier actividad humana, cualquiera que sea su distancia en el tiempo y en el espacio. Existe una frase famosa del poeta romano Terencio: "Homo sum, humanus a me alienum puto": "Yo soy un ser humano, por lo tanto no puedo ser indiferente a nada de lo que concierne a lo humano". $Y$ la fuerza de nuestra participación emocional en acontecimientos pasados no está en proporción con la proximidad de estos acontecimientos.

Volveré a ilustrar este asunto. ¿Cuáles son los seres humanos que han existido hasta ahora que tienen el mayor arrastre en nuestros sentimientos, que tienen la mayor influencia sobre nuestros actos? No son nuestros contemporíneos. No cabe duda que tenemos sentimientos fuertes respecto a diversos politicos contemporáneos o hacia estrellas de cine o atletas, pero estos sentimientos son muy efimeros. La fama de un político y aún más de un atleta o una estrella de cinc, es de corta vida. Los que tienen la mayor influencia sobre nuestras viḑas son personas que vivieron hace mucho tiempo. Nombraré cuatro personas que tienen una influencia continua sobre las vidas de casi todos nosotros en el mundo actual. Los nombrare por orden de aparición: Buda, Confucio, Jesús y Mrahoma. Nuestros sentimientos respecto a cstos cuntro fundadores de tres grandes religiones y de una gran filosolia son mucho mís profundos que aquellos que tenemos respec- 
to a eualquicra de nuestros contemporancos. $\mathrm{P}$ su influencia sobre nosotros es mucho mayor que la de cualquiera de nuestros contemporáncos.

Voy a mencionar también un caso curioso de la historia de Egipto antiguo. Como se sabe, en el siglo xw antes de la era de Cristo, existió un farán muy revolucionario, el emperador Akjenaton. Trató de revolucionar todo en la vida egipcia; trató de revolucionar el arte, usar el lenguaje vivo en lugar del usado en los documentos y sobre todo, trató de revolucionar la religión cegipcia y reemplazar el politeismo por el monoteismo. Akhenaton fue un revolucionario solitario. No tuvo nunca el suficiente arrastre $y$ al final fue derrotado. Todas sus reformas y actos revolucionarios fueron tergiversados y luego fue execrado. Su nombre fue arrancado de todos los monumentos que habia construido $y$, mientras duró la civilización egipcia, digamos después de 160 años cerca del tercer siglo de la era cristiana, Akhenaton fue recordado como un hereje, un rillano, $y$ un monstruo. En el tercer siglo de la era cristiana,.los propios egipcios olvidaron leer y escribir su escritura tradicional que habian usado durante 3.000 años. Inventaron, en cambio, un alfabeto basado en el griego. Rechazaron su religión antigua $\mathrm{y}$ adoptaron la cristiana y más tarde el islasisismo. Durante los siguientes mil seiscientos años desde cerca del tercer siglo de la era cristiana hasta el siglo dicienueve, nadie en el mundo sabia que un personaje como Akhenaton hubiese existido. Luego, alrededor de 1880, los arqueólogos desenterraron los archivos de Akhenaton en la ciudad que él mismo había construido, la cual habia sido abandonada después de su muerte, y encontraron todo lo relacionado con él. Lo interesante del asunto es que durante cstos últimos 80 años en que Akhenaton ha sido nuevamente reconocido en el mundo $y$ sus actividades han sido nuevamente conocidas, ha vuelto a ser un personaje de controversia en torno a la cual mucha gente experimenta fuertes emociones. Los estudiosos del antiguo Egipto, de mente conservadora no gustan de Alkenaton, pero a los estudiosos de mentalidad liberal o radical, les gusta mucho. Por supuesto, sus sentimientos no son tan fuertes como los de los contemporáneos de Akhenaton, quienes estaban apasionadamente en favor o en contra de él. Sin embargo, los sentimientos de los estudiosos contemporáneos de la egiptología en la época de Akhenaton, son lo suficientemente fucrtes como para enjuiciarlo en una forma no muy objetiva. Cuando uno lee lo que un egiptólogo ha cscrito sobre Akhenaton, se puede decir si este tiene una mente conservadora o liberal. Se deja llevar, de sus ideas pero no nos da una visión objetiva sobre él. De tal manera, alguien que virió en el siglo catorce a. C. y cuya existencia ha sido olvidada durante 1.600 años al ser redescubierto puede aún despertar hondos sentimientos. $Y$ ésta es ouna prueba de la veracidad del pocta Terencio al decir "Homo sum nihil humanum a me alienum puto".

Yo diria que nuestra actitud hacia los problemas humanos de cualquier epoca, no puede estar cmocionalmene desvinculada de ellos como nos susede al estudiar la naturaleza no-humana. Pero lo que podemos $y$ debemos 
hacer es cxaminar nuestros propios sentimientos y prejuicios, confesamos a nosotros mismos estos sentimientos y prejuicios asi como a nuestros lectores, si somos historiadores que publicamos nuestras obras sobre historia, de manera que el público tenga la oportunidad de excluir nuestros sentimientos $\mathrm{y}$ nuestros prejuicios. Sabrin entonces que ese historiador es tal persona, que pertenece a tal o cual clase social, que su religión es tal o cual, que es o conscrador o looeral o comunista o anticomunista. El debe tomar en cuenta estos factores al leer sus libros, y puede juzgar lo que escribe, a la luz de lo que sabe respecto del historiador. Pero el historiador y sus lectores no pueden quedar marginados, desprejuiciados o faltos de emoción al estudiar los asuntos humanos, âunque estos estén muy lejanos del presente.

Tocaré ahora el último punto. Pienso que el estudioso de la historia contemporánea, de la más reciente, debe ser también un estudioso de la más remota. Supongamos que se está tratando de escribir la historia de asuntos contemporáneos -asuntos internacionales contemporáneos, digamos por plazos de año a año- de manera que el tema inmediato sea acontecimientos que en el momento de escribirlos no tienen mayor antigüedad que. 6 a.18 meses. Al narrar la historia de cualquier periodo, tanto del pasado inmediato como del remoto, no basta registrar los acontecimientos, deben ser situados en su ambiente histórico. Se debe mostrar lo que precedió a los acontecimientos. Si estuviéramos describiendo solamente acontecimientos, sin dar su fuente histórica, sería imposible para los lectores componentes en la forma en que se tratan de describir y si uno supone que el historiador deberia dar los antecedentes de los acontecimientos así como los acontecimientos mismos, no sería posible fijar un límite retrospectivo de los hechos pasados que tienen significación para la historia actual. Es posible que para explicar algún tratado suscrito en la actualiclad, digamos el tratado sobre la participación de Estados Unidos en la industria chilena del cobre, no haya que retroceder 26 3 años. No sé. Puede que haya que retroceder 10, 20 ó 100 años. Pero se debe retroceder mucho mis: puede que 100 o aun 1.000 años.

En conclusión, daré algunos ejemplos de ello, tomados de la historia actual. Uno de los hechos que dificulta mayormente nuestra comprensión es el estado anímico actual apasionado y violento de los chinos. Ello está simbolizado en grado extremo por los llamados Guardias Rojas, pero es característico del pucblo chino en este momento. ¿Por qué los sentimientos actuales de los chinos son tan furiosos, tan encolerizados, con respecto al resto del mundo? No se puede comprender este fenómeno si sólo se mira la historia china desle que los comunistas tomaron el control del país en 1949. Para entender el estado animico del pueblo chino actual hay que darse cuenta que, durante unos 2.000 nños o más, los chinos representaban la civilización central de la mitad del mundo, la mitad que los chinos conocen, el mundo del Asia Oriental que contiene posiblenente más de la mitad de la población del planeta. Y luego en 1839 , de pronto mi pais, un paisillo 
"bárbaro" del otro lado del mundo, apareció y fuc capaz, con armas superiores, de vencer a los chinos en su campo $c$ imponer las condiciones. Lucgo, durnte 100 años, desde 1839 a 19.15 China fuc abatida y humillada por un pequeño pais "bárbaro" después de otro ("Bárbaro" descle el punto de vista de los chinos). Por Gran Bretaña, Francia y Japón. Japón ha sido el imitador de la China, pero al adoptar tácticas occiclentales, los japoneses fueron capaces de invadirla y saquearla. Lo que estamos viendo en la China actual es el resultado de esos $2 \mathrm{mil}$ años desde que China era el centro del mundo, según su propia visión, y de esos 100 años en que la posición de los chinos cambió rápidamente, durante los cuales fueron tratados como "nativos", como un pueblo subhumano. No se puede comprender el estado animico actual de China a menos que sc retroceda al último milenio a. D. Esto es muy importante al tratar con China en este momento.

Examinaré ahora, uno de los más impresionantes rasgos del período desde la Segunda Guerra Mundial: el acercamiento actual entre Ias diversas ramas de la cristiandad: entre la Iglesia Gatólica y las ramas proteśstantes, la iglesia del mundo occidental y entre las iglesias occidentales en general y las ortodojas orientales. No se puede comparar este hecho sin ir al cismo que dividió la Iglesia Ortodoja oriental de la occidental en el siglo dos de la Era Cristiana y $\sin$ necesidad de ir hasta la secesión de las IgIesias protestantes occidentales de la Iglesia Católica occidental en el siglo dieciséis. Hay que tomar en cuenta las guerras religiosas de los siglos dieciséis y diecisiete, el descrédito en que cayó la religión cristiana en el mundo occidental debido a las atrocidades y barbaries de las guerras religiosas o a las consecuentes secularizaciones que comenzaron hacia fines del siglo diecisiete y que se han ido extendiendo durante los siglos dieciocho y diecinueve. Todos estos hechos son necesarios en el panorama para comprender el cambio reciente en la. actitud de las diferentes fracciones de la Iglesia Cristiana: este cambio maravilloso del odio mutuo y la hostilidad hacia un amor fraternal y hacia una cooperación mutua para salvar a la raza humana de la destrucción.

El punto de vista actual del Presidente de Gaulle -que es un personaje de controversia, especialmente para los ingleses - no puede ser comprendido, pienso yo, sin referirnos al pasado. El año 1940 para Francia fue muy semejante al siglo diecinueve para China. Fue un periodo en el cual una gran parte del pueblo fue humillada. Tanto en Francia como en China, se observa una reacción emocional. Tal vez no en Francia como conjunto, pero ciertamente en la mente y en el corazón del Presidente de Caulle en el presente. Uds. deben recordar la parte central que jugó rrancia en la vida del mundo occidental, descle la Edad Media adelante, y los tremendos desastres que sufrieron los franceses, primero en $1570-1$ y luego en $19 \cdot 10$, si es que se quiere entender la actiud del Presidente de Gaulle.

El conflicto entre los israclitas j’ los árabes está ofreciendo al mundo una constante ansiedad, causando gran sufrimiento en los refugiados árabes que 


\section{Arnodd Toynbee $/$ El estudion de la historia conlempocáned}

han sido expulsydos de sus hogares en el ecritorio ocupado ahora por isracl. Esto no lo podtán entender sin adentrarse en la historia pasada. ¿lor qué los judios insisten en occipar este territorio limitado y cconómicamente no apreciable como es Palestina? Porque hacia fines del segundo milenio d. C., los antepasados de los judios ocuparon parte de Palestina y se manturicon alll cerca de mil años. ¿Por que los árabes están tan furiosamente resentidos al ser tratados como "nativos" que no tienen derechos sobre su propio territorio? Fan sido expulsados de su propio territorio por inmigrantes sio. nistas de Europa oriental. Los árabes están furiosos porque ellos también tienen un gran pasado del cual están orgullosos. Su estaclo actual probablemente no equivale a su pasado, lo que seguramente los hace más sensibles y más dificiles de tratar. Así, para comprender las actuales-disputas entre Israel y los árabes - la reciente lucha entre.el-ejército sirio y el israclita y la reciente agresión israelita contra jordania-, hay que ir hacia atrás, hacia el lado de los árabes hạsta antes del final del primer milenio cle la Era Cristiana, y hacia el lado de los judios hasta antes del final del segundo milenio antes de Cristo.

La presente controversia entre India y Pakistán, que recientemente los llevó a una guerra es, nuevamente, una de las situaciones que nos causa ansiedad, que. ha producido grandes miserias, ha convertido a muchos en refugiados y causando la muerte de mucha gente descle 1947, cuando las dos comunidades - los musulmanes y los hindues- fueron distribuidos entre Pakistán e India. Para comprender esto, hay que retroceder hasta la conquista progresiva de los musulmanes de gran parte de India que comenzó en el siglo dos de la Era cristiana. Hay que volver atrás hasta la época de la reacción hindú en los siglos diecisiete $y$ dieciocho. Probablemente los hindúes habrían conquistado toda la India y habrian subyugado o expulsado a los musulmanes si los ingleses no hubieran entrado y conquistado tanto a los musulmanes como a los hindues. Deben entender esto para poder compreder el cisma entre India y Pakistán.

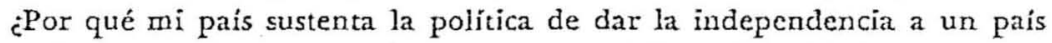
después de otro, que al principio pertenecían al Imperio Británico y eran regidos desde Londres? Porque, en el tercer cuarto del siglo dieciocho cometimos el gran error de tratar de dominar nuestras 13 colonias en Norteamérica en forma demasiado vehemente. iDe tal manera, los norteamericanos iniciaron contra nosotros una victoriosa guerra de independencia? Decidimos que no cometeriamos ese error especial nuevamente. Hemos cometido muchos crrores politicos más descle entonces, pero no esc. Asi, prinero dimos la independencia al Canadá, luego a Australia, luego a la India y al Pakistán, y ahora a los sectores africanos del Imperio Británico antes que nos obligaran a hacerlo. No esperamos esta vez que nos forzaran a cllo: la dimos en forma voluntaria antes. Para comprender esto, hay que retroceder a la historia de las relaciones entre las colonias nortcamericanas y la Gran Bretaña durante el siglo dieciocho.

Finalmente, ipor qué América Hispana -los primeros dominios del Impe- 
rio español en las Indias- la sido repartida, desde su independencia lograda hace cerca de un siglo y medio, en no menos de 18 astados soberanos independientes, separados y sucesivos? El dominio portugues en las Americas ha formado un solo cstado: Brasil. Los primeros dominios en Norteanerica han quedado reducidos a un solo estado: los Estados Unidos. Los dominios españoles se han bifurcado en 18 estados. Creo que para entender esto hay que retroceder bastante en la historia de España y darse cuenta que, aunque en el siglo quince España tenía una unidad politica, su unión era muy precaria. España continuaba siendo una asociación y no una unión de un número de reinos separados y, cuando España conquistó estos vastos territorios del Nuevo Mundo, los organizó en la misma forma en que ella estaba organizada, en un número de virreinato y capitanias generales: los virreinatos de Nueva España y Perú y eventualmente de Buenos Aires, y las capitanías generales de Nueva Granada, Chile y Cuba, las que estaban muy poco vinculadas entre sí. Asi, yo pienso que en los comienzos del separatismo de las actuales Repúblicas Americanas independientes, retrocediendo hasta mucho antes del final del gobierno español en las Américas hay que buscar los orígenes en la historia misma de España.

Así yo diría, en conclusión, que el historiador de acontecimientos muy recientes debe estar preparado - para hacer estos acontecimientos inteligibles- para retroceder en 10 ó 100 o aún 1.000 años en el tiempo. El historiador contemporáneo debe hacer uso de casi toda la historia humana. Ya Ies he dado algunas razones por qué pienso que el estudio de la historia contemporánea es posible o por qué el estudio de la historia contemporánea no es más dificil que el estudio de pasado más distante. 